\title{
Reply to Fumerton, Huemer, and McGrath
}

\section{Citation}

Siegel, Susanna. 2012. “Reply to Fumerton, Huemer, and McGrath." Philosophical Studies 162 (3) (December 2): 749-757. doi:10.1007/s11098-012-0057-7.

\section{Published Version}

10.1007/s11098-012-0057-7

\section{Permanent link}

http://nrs.harvard.edu/urn-3:HUL.InstRepos:27409222

\section{Terms of Use}

This article was downloaded from Harvard University's DASH repository, and is made available under the terms and conditions applicable to Open Access Policy Articles, as set forth at http:// nrs.harvard.edu/urn-3:HUL.InstRepos:dash.current.terms-of-use\#OAP

\section{Share Your Story}

The Harvard community has made this article openly available.

Please share how this access benefits you. Submit a story.

\section{Accessibility}




\section{Reply to Fumerton, Huemer, and McGrath \\ Susanna Siegel}

Wishful thinking, fearful thinking, and prejudice can generate ill-founded beliefs. These beliefs are ill-founded by virtue of the way that other mental states influence their formation. Once formed, they pass on their ill-foundedness to subsequent beliefs formed on their basis. I argue that the same is true of experiences. Wishful seeing, fearful seeing, and prejudiced seeing can generate epistemically downgraded experiences. Downgraded experiences are formed in ways that reduce or eliminate the rational support they have to offer. Beliefs formed on their basis are thereby ill-founded.

Huemer and Fumerton disagree. They think experiences aren't downgradable by their etiology. Wishfully seeing a gun in the fridge can provide evidence that there's a gun in the fridge. Wishful seeing can't downgrade experiences, even though wishful thinking can lead to ill-founded belief. In this respect, experiences and beliefs are asymmetrical. McGrath agrees with me, and thinks that standard evidentialists should too. He thinks that wishfully seeing a gun in the fridge disqualifies the gun-experience from providing evidence that there's a gun in the fridge. He proposes that epistemically downgraded experiences all share a common structure. The structure is designed to highlight the symmetry in rational status that we find (and Huemer and Fumerton don't find) between evidentially illfounded beliefs and epistemically downgraded experiences. And it brings into focus McGrath's reasons for thinking that evidentialists should agree that experiences would be epistemically downgraded by the cases of cognitive penetration that I describe.

After responding to McGrath's evidentialist proposal in section 1, and to Huemer's argument against the epistemic symmetries in section 2, I defend the epistemic symmetries in section 3 . I conclude by discussing the rational force of experiences that aren't defeated or downgraded.

\section{The structure of epistemic downgrades}

The centerpiece in McGrath's structure is the notion of quasi-inference, which is a relation between experiences. Perhaps these are better called "subexperiences" since they often occur simultaneously. Experiences formed by quasi-inferences are downgraded, if the corresponding beliefs formed by isomorphic inferences would result in jumping to conclusions.

Even if quasi-inferences between experiences mirror poor inferences to beliefs, some reason is needed to think that epistemically poor quasi-inferences do to experiences what poor inferences do to beliefs: namely, turn them into conduits of ill-foundedness. McGrath takes for granted that experiences and beliefs are rationally symmetrical in this way. His account of quasi-inference thus could not provide an independent defense of the Downgrade Principle. 
McGrath nonetheless presents the account of quasi-inference as a defense of the Downgrade principle, perhaps with the idea that if evidentialists appreciated just how much the "checkering" process is like a poor inference, they would agree that those experiences fail to provide evidence for believing their contents (or contents that are suitably related). His account thus challenges one putative explanation of the asymmetry thesis, namely that the etiology of belief can be inferential, whereas the etiology of experience cannot be. But it doesn't have any edge against the stronger asymmetry thesis that, even when the etiology of an experience is quasi-inferential, it still does not lead to epistemic downgrade.

McGrath's notion of quasi-inference helps illustrate why, once the Downgrade Principle is accepted, it is compatible with standard evidentialism. On this approach, downgraded experience will not count as evidence (or will not count as very good evidence). They will have that downgraded status, because they came about via a process that is isomorphic to jumping to conclusions. The jump is from information about "low-level" properties, such as color, shape, size, and texture, to representations of high-level properties, such as emotions (anger) or kinds (pliers, embryos).

Jill's experience of Jack as angry seems to be based on an experience of his looking a certain way which in fact isn't a good indicator of anger for her. There is a gap here that is filled in, or leapt across, only by the expectation that Jack is angry, not by Jill's knowledge connecting the lower-level content with the higher-level one. The preformationist sees something of a certain shape, size and texture which in fact isn't a good indicator of an embryo, but which serves as his basis for seeing it as am embryo. Here again there is a gap between the shape, size and texture features and the embryo feature, and it is only the desire to see one's theory confirmed which "closes" the gap. The pliers have a certain color, shape, and size - a certain gestalt - that not much of a good indicator of a gun, but nonetheless the subjects, on this basis, with the help of the prejudice rather than any background knowledge or perceptual ability, the subject sees the object as a gun.

Ultimately, I think the pliers, gun, and anger cases don't have to take the form of a quasi-inference (i.e., an inference from "low" to "high"), and that quasi-inference does not play a central role in illustrating the compatibility between evidentialism and the Downgrade Principle. Let me first explain why someone (perhaps McGrath) might think that quasi-inference is essential to epistemic downgrades, and thus plays a central role in illuminating their structure.

Quasi-inference is analogous in some ways to the resolution of the underdetermination problem in perception. Sensory transducers take in the earliest sensory information, and that information is compatible with a wide range of external conditions. Yet the visual system ends up with a much more determinate representation of the environment than the transducers convey. How 
does the visual system arrive at a "verdict" on how the environment is, given the paucity of initial information? This is the under-determination problem. Quasiinference is structurally similar. As McGrath thinks of it, the fact that an experience represents certain low-level properties leaves undetermined which high-level properties it represents (if any).

The under-determination problem is resolved in every case of perception. In light of this fact, one might be tempted to think that structurally similar quasiinferences also happen in every experience, and hence that epistemic downgrades are just a special subset of them.

But the analogy between quasi-inference and the resolution of the underdetermination problem is overdrawn. First, since our only experience of low-level properties includes constancies of color, shape, and size, by the time we have such experiences, the under-determination has already been at least partly resolved. Second, unlike resolutions to the under-determination problem, quasiinferences are not psychologically real transitions from a low-level experience (i.e., an experience with low-level content) at one moment to a high-level experience at the next moment. In his more extended discussion of quasiinferences, McGrath emphasizes that they are dependence relations. ${ }^{1}$ If highlevel $E^{*}$ is quasi-inferred from low-level $E$, then the fact that the subject has the low-level $E$ is supposed to help explain why she has the high-level $E^{\star}$. Typically the experiences related by quasi-inference happen simultaneously. When you see a bicycle, or your sister, these items do not usually need time to come into focus as a bicycle, or as a person.

In addition, some routes to downgraded experiences avoid faulty quasiinferences altogether. In principle, a background cognitive state could directly influence an experience (more exactly, a subexperience), from which another subexperience is quasi-inferred without any epistemic shortcoming. Suppose that prejudice made the pliers look to have the texture of a gun, or that fear made Jack's eyebrows appear furrowed in the way that provides a cue for anger. In those cases, there might be a quasi-inference from low-level to high-level contents, but it would be mediated by "background knowledge or perceptual ability". The epistemic fault would have to be found upstream, in the relationship between the background cognitive state and the experience at the start of the quasi-inference.

In other cases of cognitive penetration that are intuitively epistemically problematic, having a high-level experience could help explain why the subject has a low-level experience, where this dependence relation is again epistemically innocuous. For example, acrophobes standing on high balconies tend to overestimate their distance from the ground, compared with people standing on the same balcony who are not afraid of heights. ${ }^{2}$ The acrophobe's fear might lead

1 McGrath (forthcoming).

2 Stefanucci and Proffitt (2009). 
her to experience a balcony as being at a distance that is dangerous to fall from, and that (sub)experience might explain why she experiences the distance to the ground as magnitude $D+$. The corresponding inference is roughly that if a balcony is a dangerous height to fall from, it is pretty far off the ground - at least $\mathrm{D}+$. That inference seems reasonable. By the belief measure for downgrade, the inference is epistemically innocuous. If there is an epistemic problem, it is in the role of fear in influencing the danger-experience.

The notion of quasi-inference could be reconceived to allow desires, fears, or other states as well as experiences to be states from which experiences are quasi-inferred. This would free the notion of quasi-inference from the model of the underdetermination problem, and the resulting notion could account for these cases, as well as for downgrades that are located where McGrath finds them, in the poor low-to-high quasi-inference. I think McGrath resists this suggestion because he worries it will overgenerate, by classifying as irrational processes in which a desire to believe that the lights are on leads one to turn on the lights, thereby generating what should be perfectly good evidence that the lights are on. In this case (suggested originally by Feldman 2000), a desire influences the contents of experience, but not in any way that should downgrade that experience. For downgrade to occur, McGrath says, "The influence of the directional goal must, at the very least, occur internally, i.e., after the initial stimulation of sensory receptors" - which is what leads him to his notion of quasiinference.

But it is not necessary to move to the overly restrictive notion of quasi-inference to exclude Feldman's sort of case from the category of checkered experiences, because it can be ruled out by my isomorphism requirement on such experiences. When we compare etiologies of experience and belief, it isn't enough for the psychological elements to be isomorphic. The psychological mechanisms have to be isomorphic as well. In Feldman's case, the mechanism by which desire influences belief crucially includes the intentional act of turning on the lights. The isomorphic etiology of experience would include the same act: desire to experience a well-lit room could influence the contents of experience by leading you to turn on the lights. In contrast to these epistemically innocuous forms of influence by desire on belief and experience, a different form of influence leaves out the manipulation of perceptual stimuli, and the desire influences the belief or experience directly. This would be a case of wishful thinking for belief and wishful seeing (or hallucinating) for experience. Nonhallucinatory cases will involve external perceptual stimuli as well. But the root of the epistemic problem lies in the influence by the desire on the experience of light.

\section{What is one supposed to believe in response to a checkered experience?} Huemer objects to the idea that experiences are susceptible to downgrade in the ways McGrath and I describe. He observes that when one's experience is 
undefeated, it will seem rational to endorse it, and irrational to suspend judgment or disbelieve one's eyes. Given that the subject has an undefeated gunexperience, what other doxastic response to it could possibly be rational, other than endorsing it?

This objection to the Downgrade Principle is the "What am I supposed to think?" objection, labeled aptly by McGrath. The objection assumes that any rational doxastic response to an experience has to present itself as such to the thinker. Huemer's version of this assumption appears in Premise 6 of his argument ( $E$ is the proposition that an egg carton is in the fridge, $G$ is the proposition that a gun is in the fridge):

(6) If $S$ would have no rational way of explaining why she believed $E$ while refusing to accept $G$, then $S$ would be irrational to believe $E$ while refusing to accept $\mathrm{G}$.

Premise (6) assumes that a doxastic response is rational for $\mathrm{S}$, only if $\mathrm{S}$ has a rational way to explain why she adopts it. This assumption is at odds with a direct consequence of the Downgrade Principle. If $S$ 's experience is downgraded relative to $G$, and so doesn't provide rational support for $G$, then what $S$ epistemically ought to do is suspend judgment on $G$, even if she has no rational way of explaining why that option is rational. (Here I am assuming $S$ never had such strong prior reason to doubt that there's a gun in the fridge that it would have defeated her experience to begin with).

The assumption that a subject has to be able to explain why her doxastic responses are rational seems doubtful. Consider wishful remembering - the analog for memory of wishful thinking and wishful seeing. ${ }^{3}$ In McGrath's talented children example, what a subject explicitly remembers seems rational to her, but is intuitively made irrational by virtue of her unretrieved memory of the other talented children in the piano class. Even though this memory is unretrieved, it intuitively provides a defeater for the belief that the thinker's child is the most talented student in the class.

Another type of example involves the inferential blindness that can accompany some types of compartmentalized beliefs. Suppose you believe you have an hour-long appointment with $\mathrm{X}$ alone at noon, and you also believe you have an hour-long appointment with $Y$ alone at noon, but you fail to realize that you have conflicting appointments until $X$ and $Y$ both appear at your door. ${ }^{4}$ Intuitively, your belief that you will spend the midday hour with $X$ (your $X$-belief) retains its rational force relative to your belief that you will spend the midday hour with $Y$ (your Y-belief), and vice-versa. In light of your X-belief, your Y-belief is irrational.

3 Kunda (1990).

4 This type of case is discussed in Silins and Siegel (forthcoming), and Siegel (forthcoming). 
Yet at the moments when you remembered your appointment with $X$, it seemed rational to maintain your X-belief.

Internalists are divided on how wide a range of mental factors belong to the base on which facts about justification supervene. Some forms of internalism allow that person-level psychological configurations that are beyond what the subject has easy access to can affect the rational status of her beliefs. The Downgrade Principle fits naturally with such a version of mentalist internalism. Of course this type of mentalist internalism could also reject the Downgrade Principle, on the grounds that mental factors other than checkered experiences can affect what the subject has justification to believe, even when the subject fails to have easy access to them. ${ }^{5}$

Huemer's Premise (6) entails that the principle is false, and Huemer provides no independent support for it. On the other side, McGrath's account of quasiinference does not provide independent support for the Downgrade Principle, since it entails that the principle is true. And so we come to the central issue: do the same etiological factors that lead to ill-founded beliefs downgrade experiences as well?

\section{Why experiences can be downgraded by their etiology}

In defending the Downgrade Principle, my argumentative strategy is to focus on the features of beliefs that distinguish them from experiences, and argue that none of these features of beliefs ground their status as potential conduits for illfoundedness. Since beliefs must have some underlying features that explain what makes them this kind of conduit, if we don't find this explanation among the distinctive features of beliefs, then they must be found among their nondistinctive features. And if they are found among non-distinctive features, that opens the possibility that experiences have those features as well.

McGrath and Fumerton say that I overlook an obvious candidate for a distinctive feature of belief that explains what makes them conduits of ill-foundedness: the fact that beliefs can be irrational (or unjustified), whereas experiences cannot. McGrath asks, "how can we hold fixed the irrational etiology while manipulating the belief's status as unjustified to see if it still makes beliefs based on it unjustified? We can't." I agree that in a case where the entire basis of an illfounded belief B2 is another belief B1, B1 has to be ill-founded, and therefore unjustified (irrational). But that fact doesn't show that the status of B1 as irrational is explaining what makes B2 ill-founded.

5 Besides checkered experiences, highly inattentive experiences might also impact the rational status of beliefs that fail to take into account (an issue discussed in Silins and Siegel (forthcoming)), or experiences of situations that are bypassed in the formation of beliefs about those situations (Siegel forthcoming). 
What does explain why beliefs are susceptible to ill-foundedness, and experiences are susceptible to downgrade, if not any susceptibility to being irrational?

My answer is that the psychological role of experiences and beliefs is so similar that it grounds their role as conduits in the same way. It is uncontroversial that experience typically leads to belief. We tend to believe our eyes, and when we do, the cognitive roles of experience are a subset of the cognitive roles of beliefs. Like beliefs, experiences provide input to the reasoning (including action plans) that we actually go through - whether that reasoning conforms to epistemic and practical norms or not. It is a psychological fact about us that when we experience a gun in the fridge - really experience one, as Huemer tries to depict with his photograph - we are generally disposed to act as if there is a gun in the fridge, and to take it for granted that there is a gun in the fridge in our other plans. We could sum up this shared psychological role by saying that both experiences and beliefs are endorsements of contents.

Of course sometimes, epistemic rationality dictates that we quarantine experiential endorsement, so that it does not interact in the usual ways with our other beliefs and with our behavior. For instance, if we know or have reason to think that there can't be a gun in the fridge, then rationality dictates that we ignore how things seem. ${ }^{6}$ Often in these situations, the norms of epistemic rationality are difficult to adhere to. Even if you know that a mirage is making it look as if water is ahead, or even if you have excellent reason to think so, it may nonetheless be difficult for you not to act as if it is water is ahead. Some partlycured schizophrenics report that they were better able to ignore the voices in their head, after taking medication that reduced the auditory volume of those voices. ${ }^{7}$ When the voices were loud and clear, they were hard to ignore; when they were still heard but heard more softly, it was easier to respond to them as symptoms of a disease, rather than as part of reality. The cognitive role of these experiences play is largely the same as the role of beliefs.

Fumerton may have something like these psychological symmetries in mind, when he suggests that if experiences had contents (which he doubts, but grants for the sake of argument), then that feature alone would make them susceptible to downgrade, by making them assessable for rationality as well. "Once one does [think of experiences as intentional states], it is no longer so obvious that one couldn't think of them as rational or irrational (the way one sometimes thinks of

6 Similarly, practical rationality might recommend that we quarantine our beliefs similar ways, for instance when it seems best to go along with a group plan to head to the movies even if you think the movie theater got torn down. 7 I first heard this reported by a patient who was being interviewed by his psychiatrist Donald Goff at a Harvard Mind, Brain, and Behavior Symposium, in the Fall of 2007, who told the symposium that such reports are common. See also Siris and Acosta 2012. The general phenomenon in which vivid experiences are difficult to ignore is described and predicted by Maher 1999. 
fears, for example, as rational or irrational)." I think this suggestion can't be quite right as it stands, because a state can have accuracy conditions, even if it does not play the role of an endorsement. Consider suppositions, such as those we make for the sake of argument, or for the sake of having a stable assumption to operate under when uncertainty is not practically viable. Suppositions can be accurate or inaccurate, and it may be wise or unwise to make them. But this kind of wisdom (or lack thereof) seems to be practical, rather than indicating epistemic rationality or irrationality. Suppositions do not contribute to the subject's overall point of view on the world in the way that experiences and beliefs do. Beliefs or even fears and desires might be conditionally rational, given a supposition, but the supposition itself does not seem assessable for rationality. What matters for being conduits of rationality isn't having accuracy conditions, but having the psychological role that is common to experience and belief - the endorsement role.

Could experiences play the endorsement role, if they didn't have accuracy conditions? They could, but the occupant of that role would have to be the experience supplemented with beliefs that "interpret" it. Consider Fumerton's suggestion that the subjective character of experience is exhausted by sensations that are not assessable for accuracy. In Fumerton's words, they would lack the capacity to "correspond or fail to correspond to reality." This conception would fit with a traditional indirect realist theory, on which when you see pomegranates, they typically cause in you qualia (raw feels) that you come to learn are correlated with pomegranates. ${ }^{8}$ Here, the belief-like outputs would be performed by qualia paired with an "interpretive" belief. This pair would feed into behavior and reasoning. The occupant of this belief-like role would be the experience supplemented with beliefs that "interpret" it.

Qualia paired with 'interpretive' beliefs could also be susceptible to cognitive penetration, in the same ways as experiences are on the assumption that they have accuracy conditions of their own. In principle, either the qualia themselves, or the accompanying interpretive beliefs, or both could be influenced by desires or fears. For instance, in this framework, Jill's fearful seeing could take the form of believing that her qualia (which in fact are normally caused by neutral expressions) are on this occasion caused by Jack's anger. Or it could take the form of having qualia that are normally caused by angry expressions, but are on this occasion caused by Jack's neutral expression. So while having accuracy conditions makes experiences autonomous modes of endorsing contents, experiences without accuracy conditions could form part of a complex unit that plays a similar psychological role.

8 Qualia are supposed to be aspects of experience that characterize our experience, independently of how the external world seems to us. But exactly analogous points hold for experiences construed as relations to sense-data, where these are mental objects that we perceive, and thereby perceive the external objects that cause them. 


\section{Conclusion}

I've argued that the Downgrade Principle is true, and that it is compatible with various forms of internalism about justification. (That it is compatible with reliabilism seems obvious). But if the Downgrade Principle is true, a major question remains. When an experience is not downgraded or defeated, what gives that experience (or the experiences plus other factors) the power to provide rational support for believing its contents?

Some phenomenal conservatives suggest that phenomenal character itself is a source of rational power, bestowing experiences with rational support for believing their contents (or closely related contents), absent defeaters. ${ }^{9} \mathrm{~A}$ less liberal suggestion it that rational powers are conferred on experiences by their phenomenal character, together with background beliefs (or "entitlements") that we could not fail to have. A third suggestion is that endorsing states in general have rational powers, just by virtue of playing the endorsing role. Since beliefs are endorsing states, this position would be a thorough-going form of conservatism, encompassing both experiences and beliefs.

None of these explanations is available, if the Downgrade Principle is true. The Downgrade Principle allows that experiences could have their phenomenal character, play the endorsing role, lack defeaters of the relevant sort, and be accompanied by general background beliefs - all while failing to provide rational support for believing their contents. Like many other theories of perceptual justification, phenomenal conservatism and its less liberal cousin could be adjusted to accommodate the Downgrade Principle, by restricting the class of experiences on which rational support is bestowed by phenomenal character (or by phenomenal character plus general supplementary beliefs).

A different proposal is that when the etiology of an experience is a-rational, rather than rationally assessable, it bestows rational powers on the experience. This proposal is compatible with the Downgrade Principle, but is arguably false on independent grounds. Consider someone who undergoes the following perverse train of thought, fueled by an underlying association of Black men and crime..$^{10}$ While watching a film about Black nationalism, he suddenly wonders whether he remembered to lock the car. After the film, he is about to get in his car to drive home, when the same underlying association causes him to see the car door (which is in fact shut tight) as jutting out farther than normal from the car body, as if the door were not shut properly. The etiology of this experience is more like an a-rational association between thoughts than a poor inference. Yet arguably, the misaligned-door experience is downgraded by the influence of the association.

9 Pryor 2001. On rational support that experiences provide for contents that are distinct but closely related to their own, see Silins 2011.

10 Eberhardt 2004 provides experimental evidence that something this association is widespread. 
A last proposal is that the rational powers of undefeated, non-downgraded experiences is a leftover from the fact that in an intuitive sense, experiences typically enjoy a kind of rational priority when it conflicts with prior beliefs. Sometimes beliefs rationally defeat experiences - such as when you know that the watery appearance in the desert is a mirage. More often, when an experience and prior belief conflict, it is rational to update your belief by privileging your experience. You thought there was no mustard in the fridge, but then saw some mustard there once you looked inside, and that changed your mind. In general, when beliefs and experiences have the same subject-matter, we treat the experiences as ultimate arbiters of the beliefs. It's plausible to think that in general, perception has to give us a kind of access to that subject-matter that can rationally override opposing beliefs (or disprove opposing hypotheses), or else it would not match our concept of perception. If we learned that downgraded or defeated experiences were the norm, rather than being phenomena that occur only around the edges, our concept of perception would need adjustment - as would our reliance on perception in testing empirical hypotheses.

At a general level, the rational priority of experience over belief seems to derive from having access to the environment that is not obscured by what we antecedently believe, feel, want, or happen to be thinking about. Yet the priority does not explain why individual experiences have rational power, by identifying instances of that type of access. Veridicality is the simplest form of access, yet it is neither necessary nor sufficient for conferring rational powers. It seems more illuminating to say that an experience provides rational support for its content, when it is close enough to a paradigm of perception, leaving the status of perception in general as providing such a support as an explanatory primitive."

\section{Works Cited}

Eberhardt, J. et al. 2004. "Seeing Black: Race, Crime, and Visual Processing" Journal of Personality and Social Psychology, Vol. 87, No. 6, 876-893.

Feldman, R. 2000. "The Ethics of Belief," Philosophy and Phenomenological Research, 60 (3), pp. 67-695.

Kunda, Z. 1990. "The Case for Motivated Reasoning," Psychological Bulletin 108, 3:480-498.

Maher, B. 1999. "Anomalous experience in everyday life: Its significance for psychopathology," The Monist, 82: 547-70.

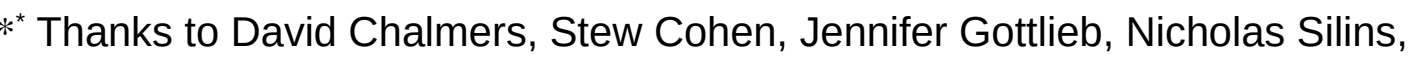
Declan Smithies, Scott Sturgeon, and especially Matthew McGrath for discussion. 
McGrath, M. "Phenomenal Conservatism and Cognitive Penetration: The Bad Basis Counterexamples". Forthcoming in C. Tucker, Ed. Seemings and Justification. Oxford University Press.

Pryor, J. 2001. "The Skeptic and The Dogmatist" Nous 34 (4): 517-549.

Siegel, S. "Can Selection Effects on Experience Influence its Rational Role?" Forthcoming in Gendler, T. Oxford Studies in Epistemology 4. Oxford University Press.

Siris, S. and Acosta, F. "Qualitative content of auditory hallucinations and suicidal behavior in schizophrenia" Schizophrenia Research 134 (2012) 298-299.

Silins, N. and Siegel, S. "Consciousness, Attention, and Justification". Forthcoming in D. Dodd and E. Zardini. Contemporary Perspectives on Scepticism and Perceptual Justification. Oxford University Press.

Silins, N. 2011. "Seeing Through the 'Veil of Perception"'. Mind 120 (478):329367.

Stefanucci, J. K., \& Proffitt, D. R. 2009. The roles of altitude and fear in the perception of height. Journal of experimental psychology. Human perception and performance, 35(2), 424-38. 